\title{
Perceptions of learning disability nurses and support staff towards people with a diagnosis of schizophrenia
}

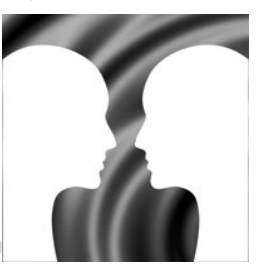

32 S.MCCORKINDALE${ }^{1}$, M. P. FLEMING ${ }^{2} \&$ C.R. MARTIN ${ }^{3}$ (D)

$4 \quad{ }^{1} X x x x x$, Inverclyde Community Learning Disabilities Team, Cathcart Centre, Greenock, UK, ${ }^{2} X x x x x$, School of Nursing, Midwifery and Social Care, Edinburgh Napier University, Edinburgh, UK, and ${ }^{3} X x x x x$, Faculty of Society and Health, Buckinghamshire New University, Uxbridge, Middlesex, UK

Keywords: learning disabilities, schizophrenia, staff perceptions

Correspondence:

C. R Martin

Faculty of Health and Society

Buckinghamshire New University

Uxbridge Campus

Room 2.11

106 Oxford Road

Uxbridge, Middlesex

UB8 1NA, UK

E-mail:colin.martin@bucks.ac.uk

Accepted for publication: 24 February 2017

doi: $10.1111 /$ jpm.12381
Accessible summary

What is known about the subject?

- People with learning disability are more likely than the general population to develop schizophrenia.

- Personal recovery philosophies are based on positive attitudes and an optimism that recognizes and values people and their strengths and capacity to achieve goals.

- Little is known from previous studies about the illness perceptions of learning disability practitioners who work with people that experience both a learning disability and schizophrenia.

- The illness beliefs of learning disability practitioners about schizophrenia may mediate the potential for social exclusion and limit recovery outcomes.

What this study/paper adds to existing knowledge?

- The findings show that the illness beliefs of learning disability practitioners and support workers regarding schizophrenia are pessimistic in terms of the consequences for people with schizophrenia and learning disability and their relatives as well as the chronic course of the illness.

What are the implications for clinical practice?

- This study identifies the nature of LD practitioner perceptions about schizophrenia and provides guidance about how personal recovery philosophies can be applied to the management of LD and schizophrenia.

- The beliefs of learning disability practitioners and support workers regarding schizophrenia need to be reframed to support better recovery outcomes and social inclusion for this group.

- The findings from this study can inform the development of training in bio-psycho-social models of schizophrenia, recovery approaches, family/carer interventions, clinical supervision, mentorship and reflection on clinical practice, which could be potentially useful strategies to help facilitate a reframing of beliefs.

\section{Abstract}

Background and purpose of study: The prevalence of schizophrenia in people with learning disability is $3-4 \%$. This is the first study to investigate the illness perceptions of learning disability (LD) practitioners towards people with schizophrenia. Methods: Learning disability practitioners $(n=210)$ that work with people with LD and schizophrenia completed a modified version of the Illness Perception Questionnaire Schizophrenia Carers Version (IPQ-SCV). Descriptive and correlational analyses were conducted for all of the IPQ-SCV subscales. Results: A significant positive correlation was found between consequences relative and consequences 
patient $(0.495, P<0.001)$, and a negative correlation was found between timeline episodic and timeline chronic $(-0.243, P<0.001)$ subscales. Discussion: Consistent with previous evidence found regarding negative staff attitudes to schizophrenia recovery outcomes, course and chronicity, the current investigation has extended and confirmed these observations to staff working with individuals with comorbid schizophrenia and learning disability. Implications for practice: This study identifies the nature of LD practitioner perceptions about schizophrenia and contributes to the development of the recovery philosophy in relation to the management of LD and schizophrenia. The findings inform the design of training modules in bio-psycho-social models of schizophrenia, recovery approaches, family intervention, clinical supervision and reflection. These can help LD practitioners to reframe their schizophrenia/LD illness beliefs.

\section{Introduction}

The prevalence of schizophrenia within learning disability populations and the need to develop a personalized, optimistic and inclusionary recovery approach $(\mathrm{DoH}$ 2001; Scottish Government 2012) support the rationale for developing personal recovery focused interventions within learning disability services. The illness perceptions of learning disability practitioners regarding schizophrenia are particularly relevant because they can influence recovery-based outcomes towards people with comorbid learning disability and schizophrenia (Sideras et al. 2015).

The prevalence of schizophrenia in people with LD ranges between 2.6 and $4.4 \%$ and is up to three times higher than it is for the general population (Deb et al. 2001, Smiley 2005, Morgan et al. 2008, Welch et al. 2011). People with mild-moderate learning disability are more likely to be diagnosed with schizophrenia than people with more profound learning disability (Cooper et al. 2007, Morgan et al. 2008).

People with LD and schizophrenia experience positive symptoms (such as voice hearing and delusions) for a longer duration, more serious negative symptoms (such as poverty of speech and blunted affect) and have poorer psychosocial outcomes compared to those with schizophrenia alone (Bouras et al. 2004, Welch et al. 2011).

\section{Principles of personal recovery}

Personal recovery approaches are based on optimistic philosophies, which offer the opportunity to support people with LD and schizophrenia to regain a sense of personhood, citizenship, inclusion, social engagement and the achievement of meaningful life goals (Leamy et al. 2011, Slade et al. 2015). Clinical interventions informed by personal recovery and person first approaches are based on five recovery processes: connectedness, hope and optimism about the future, identity, meaning in life and empowerment (Leamy et al. 2011). Therapeutic optimism is one of the key principles of recovery as is a strengths and assets-based approach. These require a recognition of the value and potential of people when helping to support people with $\mathrm{LD}$ and schizophrenia in their recovery (NIHME 2005).

\section{The role of families and carers in supporting personal recovery}

Family/carers have a pivotal role within the process of facilitating recovery (Anthony 1993, NIHME 2005). They can help to plan for goal achievement, engagement with recovery plans and emotional support and encouragement. However, the stress and burden felt by families and carers can manifest itself in communication and behaviours that have an adverse effect on the emotional environment, which is a significant risk factor for relapse. The presence of learning disability itself in a relative can have a significant impact for family carers (Emmerson et al. 2004). The emotional environment of households in relation to caring for a person with schizophrenia has been formalized within the index of expressed emotion (Amaresha \& Venkatsubramanian 2012). High levels of expressed emotion in the form of criticism, hostility and emotional over involvement/overprotectiveness are a direct corollary of the stress and burden of caring for someone with schizophrenia (Barrowclough \& Hooley 2003). Evidence from a number of studies and reviews have found that family interventions aimed at providing information, goal setting, stress management, problem solving and changing communication can have a positive effect on the emotional environment, family and carer burden and reduces relapse (Pharoah et al. 2010). 


\section{The implementation of person-centred recovery approaches within LD services}

Person first philosophies, which promote inclusion, choice and independence have been promoted within LD policy drivers for the last decade (DoH 2001, 2009; Scottish Recovery Network 2010; Handley et al. 2012).

Where person-centred recovery approaches have been implemented using a whole systems approach including training, the use of recovery champions and using an established recovery model such as the 'Recovery Star' have had some beneficial effects for the service (Esan et al. 2012). As the recovery journey is different for each client group, an understanding of the lived experience of recovery and its meaning for people with combined LD and mental health problems is paramount to the development of supportive recovery-based interventions (Handley et al. 2012). This understanding needs to be developed further within LD services. Developing an understanding of the lived experience of recovery is made more difficult by the barriers to engagement with recovery approaches caused by acute phases of illness and for people with moderateto-severe LD (Esan et al. 2012).

\section{Staff attitudes to schizophrenia in nonlearning disability settings}

Illness attitudes and beliefs regarding the chronicity, severity and prognosis of schizophrenia can lead to lower expectations (Social Exclusion Unit 2004). Lower expectations can undervalue the strengths and potential of people with schizophrenia and have a negative effect on goal setting, planning for recovery and therapeutic outcomes for people with schizophrenia (Sideras et al. 2015).

Combined LD and schizophrenia could be considered as being a 'double jeopardy' diagnostic label. Both are perceived separately as chronic, severe and debilitating conditions. In particular, interpretations of the Kraepelinian view of schizophrenia with a gradually deteriorating course and intellectual deterioration (Bentall 2009) can contribute to the development of pessimistic attitudes about potential for recovery. Experiencing the two together as comorbid conditions is likely to further promote the adoption of pessimistic beliefs about the capacity for recovery and goal achievement (Handley et al. 2012). The actual presentation of these combined conditions includes more severe positive and negative symptoms, social functioning deficits, interpersonal difficulties and challenging behaviour and may equate in staff members minds to the 'prognosis of doom' identified by Andresen et al. (2004).

A vicious cycle exists whereby the assumptions generated from these negative perceptions of schizophrenia and learning disability limit the intention to support personal and social recovery. The lack of intention then inhibits the personal achievement of goals and recovery, which increases the risk for the development of further stigma, social isolation, poorer clinical outcomes, social withdrawal and poorer social, general and occupational functioning (Clark 2007, Handley et al. 2012, Scottish Government 2013). This cycle confirms the low expectations associated with perceptions that emanate from the diagnostic label and the comorbid presentation.

Low expectations relating to employment and overcoming social isolation have been implicated in the development of stigma and increasing social exclusion for people with mental illness (Social Exclusion Unit 2004), particularly for people with a diagnosis of schizophrenia who have reduced opportunities for employment, education and community activities (Killaspy et al. 2014, Sideras et al. 2015). Social isolation and lack of opportunities caused by exclusion and its effects on self-esteem, stigma and opportunities for reality testing may also contribute to the maintenance of schizophrenia symptoms.

\section{What is known about LD staff attitudes?}

It is unclear from contemporary evidence if there are particular illness attitudes that LD staff hold in relation to people with a comorbid LD and schizophrenia and how these may affect recovery outcomes. This represents a significant and clinically relevant gap in the literature. LD staff are not a homogenous group and vary in terms of age and levels of experience, work history and clinical area. These factors may also influence the formation and maintenance of attitudes. Staff from mainstream LD services delivering mental health care to people with LD were found to have positive attitudes regarding the provision of mental health care in comparison with mainstream service staff these attitudes were mediated by their amount of contact with people that had LD and training (Rose et al. 2012). This study measured attitudes to mental illness rather than schizophrenia and so cannot provide data on specific attitudes of LD staff towards people with schizophrenia. Other studies have explored the attitudes of mental health nurses only towards people with schizophrenia (Linden \& Kavanagh 2012). No study has investigated the illness perceptions and attitudes of LD staff towards people with LD and schizophrenia.

\section{Aim and purpose of the study}

The research aim is as follows:

- To use a modified version of the Illness Perception Questionnaire (Barrowclough et al. 2001a) to identify 
the illness perceptions of learning disability practitioners and support workers working in health and social care towards schizophrenia.

\section{Methods}

\section{Ethical considerations}

Ethical approval for the study was received from the authors' academic institution, The local NHS Research \& Development department confirmed that the study would not require ethical approval from the NHS as it was not a study on patients. However, all research conducted within the NHS must be authorized by NHS Research \& Development prior to commencement. The NHS Research \& Development department authorized the study following submission and review of the completed IRAS application and information leaflet and consent forms.

The study could not identify any risks to participants provided the inclusion and exclusion criteria were adhered to. As there is a dearth of evidence related to illness perceptions of LD staff towards LD and schizophrenia, new findings could benefit patients and staff whilst no significant risks were identified (National Institute of Mental Health 2009).

\section{Design}

A cross-sectional survey design was employed with all participants being registered nurses or nursing assistants from NHS services or team leaders and support staff from social care working with people with LD. The study did not include other professional groups working with people with $\mathrm{LD}$, as the researchers were primarily interested in the illness perceptions of the groups included.

The following inclusion criteria applied:

- Registered nurses working with adults with LD

- Nursing assistants (NHS staff)

- Support workers (social care staff)

- Team leaders (social care staff with management responsibility for support workers)

- Had direct current or previous experience of supporting an adult with LD and schizophrenia.

- Currently working in the field of LD.

- Limited to staff working in a single Scottish Health Board geographical location.

In order to test a medium effect size of 0.3 with an alpha level set at 0.05 to give the study $0.8(80 \%)$ power, it was calculated that the study would require a sample of 90 (Clark-Carter 2010). To account for missing data, a stretch factor of an additional 18 participants was required. It was planned that part of the study would involve factor analysis. To adhere to standard convention and ensure full rigour of the study, a minimum sample size of 200 was identified (Kline 2000) as the psychometric properties of the modified IPQ have not been confirmed in LD staff groups, this being consistent with factor analytic approaches to instrument evaluation (reported Martin et al. 2016).

\section{Measures}

The Illness Perception Questionnaire (IPQ) and its more recent update the Revised IPQ (IPQR) (Moss-Morris et al. 2002) was originally developed to assess illness perception from the patient's point of view. The IPQ is based on selfregulation theory (Levanthal et al. 1997). Leventhal's selfregulation model condensed the patient's illness beliefs into five main categories (1) 'illness identity' (2) 'cause' (3) 'timeline' (4) 'consequences' (5) 'controllability' and 'curability'.

A modified version of the Illness Perception Questionnaire - Schizophrenia Carers Version (IPQ-SCV) (Barrowclough et al. 2001a) was used which included an additional section on study participant demographic data (Fleming et al. 2009). Agreement to use the modified IPQ$\mathrm{SCV}$ was given by the main author of the Fleming et al. (2009) study. The revised version of the original IPQ, which became the IPQ-R was then further adapted by Lobban et al. (2005) to make it more appropriate to use with relatives of people with a diagnosis of schizophrenia. Further modification of the wording of the IPQ-SCV was carried out by Fleming et al. (2009) adding two questions to the 'consequences patient' subscale to identify recovery focussed illness perceptions in practitioner's (Scottish Recovery Network 2012). The final modified version of the IPQ-SCV includes:

- Consequences patient - items refer to effects of illness on economic, functioning and life outcomes.

- Consequences relative items refer to impacts of illness on the self-perception, economic and lifestyle aspects for relatives.

- Control cure of illness-items refer to the perceived magnitude of control over symptoms and illness by the person with the illness.

- Control cure by the practitioner items refer to the magnitude of control over outcomes of the practitioner and treatment interventions.

- Timeline chronic items refer to perceived temporal aspects of the illness and symptoms.

- Timeline episodic items refer to temporal changes in the improvement and severity of the illness. 


\section{IPQ-SCV score profile}

Participants are offered a five-point Likert scale response, which includes strongly agree, agree, neither agree nor disagree, disagree and strongly disagree. Eleven of the 25 items within the modified IPQ-SCV state, the illness outcome in positive terms and therefore the scoring for these items are reversed scored to ensure a consistent scoring approach across the whole modified IPQ-SCV.

A section on demographic data was included for all participants to complete. This included age, gender, service area, length of service, whether the participant held a qualification or not, profession, years postqualification and finally whether the participant had received any additional mental health or recovery focussed training.

\section{Procedure}

The investigator contacted managers of NHS, local authority and voluntary services to adults with LD. The investigator briefed the manager on the study outline and sought permission to contact the appropriate staff in their teams regarding the study. Team managers and leaders were then emailed the participant letter introducing the study, participant information sheet that included more details on the study itself including risks, benefits, informed consent and confidentiality.

Once approval to approach staff was obtained, the investigator attended team meetings and provided a 10min presentation to inform potential participants about the research study. Paper copies of participant letter, study information sheet, participant consent form and modified IPQ-SCV were then handed out to all potential participants by the investigator, and participants were asked to read these forms before agreeing or not agreeing to participate. The investigator then left the clinical area prior to the completion of the consent forms and IPQ-SCV forms in order to avoid any influence or bias and arranged to return to the team within 3 days to collect any completed forms.

\section{Statistical analysis}

Descriptive statistical findings for scale measures will be summarized, specifically mean, standard deviation and range. Cronbach's (1951) alpha was used to evaluate the internal consistency of the modified IPQ-SCV subscales. In the modified IPQ-SCV, the items in each subscale are combined using statistical software to give mean scores for each of the subscales. Spearman-Brown coefficient was employed to calculate the internal reliability of the three IPQ-SCV subscales that comprised of just two items (Eisinga et al. 2013). Data were analysed using PASW Statistics 18 statistical software (SPSS 2009). Correlations between IPQ-SCV subscales were evaluated using Pearson's $r$ correlation coefficient. Given the number of correlations evaluated, reducing the likelihood of type 1 error was achieved by establishing a more conservative $P$ value of statistical $(P=0.001)$.

\section{Results}

\section{Response rates to survey}

There were 210 completed consent forms and IPQ-SCV's returned which was an overall response rate of $95.4 \%$ which was sufficient to identify correlations and make inferences from the data gathered as long as the sample is representative (Sivo et al. 2006).

The mean age of the study participants was 46 (8.17) years and ages ranged from 23 years to 63 years. More than three-quarters of the participants were aged $40+$, and more than a third of males and females $37.8 \%$ in both cases) were aged over 50 years. Over half of all participants $(52.1 \%)$ were qualified nursing staff with 104 of the 109 qualified nurses being LD nurses. Unqualified staff made up $37.8 \%$ of the total participants and the remaining $10 \%$ had social care qualifications. A total of 104 $(49.5 \%)$ worked in in-patient units, compared to 55 $(26.2 \%)$ from community teams.

Table 1 provides details of the gender and age characteristics of the sample.

\section{Internal consistency of modified IPQ-SCV}

The internal consistency in terms of Cronbach's alpha for each subscale of the modified IPQ-SCV and SpearmanBrown where required are reported below and show values that range from unsatisfactory $\alpha=0.496$ to very good $\alpha=0.862$ (Table 2) (Kline 2000).

Table 3 shows the mean score and standard deviations for the combined responses to individual items in each subscale of the modified IPQ-SCV. The mean scores range from 4.042 (1.510) for the timeline chronic subscale to 13.136 (3.051) for the consequences patient subscale. Comparing the mean scores with the actual maximum score possible provides a gauge of the actual level of illness perception and these differences range from 1.593 difference for the timeline episode subscale to a difference of 31.86 for the consequences-patient subscale indicating relative negative perception in terms of a lack of optimism for the patient in terms of consequences of having schizophrenia. 
Table 1

8 Characteristics, place of work and professional status of participants

\begin{tabular}{llc}
\hline Gender & Male & $71(34 \%)$ \\
& Female & $138(65.6 \%)$ \\
& Total & $1(0.4 \%)$ \\
Age range & Male & $210(100 \%)$ \\
$20-29$ years & $2(2.8 \%)$ & Female \\
$30-39$ years & $10(14 \%)$ & $8(5.8 \%)$ \\
$40-49$ years & $32(44.8 \%)$ & $11(7.7 \%)$ \\
$50-59$ years & $23(32.2 \%)$ & $64(44.8 \%)$ \\
$60+$ years & $4(5.6 \%)$ & $49(34.3 \%)$ \\
Clinical area & Community team & $5(3.5 \%)$ \\
& Specialist team & $55(26.2 \%)$ \\
& In patient & $8(3.9 \%)$ \\
& Social care & $104(49.5 \%)$ \\
Professional status & Missing & $42(19.9 \%)$ \\
& Total & $1(0.5 \%)$ \\
& Nonprofessional & $210(100 \%)$ \\
& Nonprofessional & $79(37.6 \%)$ \\
& (with SVQ or HNC) & $21(10 \%)$ \\
& RNLD & $100(47.6 \%)$ \\
& RNMH & $5(2.4 \%)$ \\
Additional mental & RNLD+ RNMH & $4(1.9 \%)$ \\
health/recovery & Missing & $1(0.5 \%)$ \\
focussed training & Total & $210(100 \%)$ \\
& Yes & $62(29.5 \%)$ \\
& No & $113(53.8 \%)$ \\
& Missing & $35(16.7 \%)$ \\
& Total & $210(100 \%)$ \\
\hline
\end{tabular}

RNLD, Registered Nurse Learning Disabilities; RNMH, Registered Nurse Mental Health; SVQ, Scottish Vocational Qualification (Health \& Social Care); HNC, Higher National Certificate (Health \& Social Care).

Table 2

Reliability (internal consistency) Statistics for Modified IPQ-SCV

\begin{tabular}{llll}
\hline IPQ subscale & $\begin{array}{l}\text { No of } \\
\text { items }\end{array}$ & Cronbach's $\alpha$ & $\begin{array}{l}\text { Spearman-Brown } \\
\text { coefficient }\end{array}$ \\
\hline Consequences patient & 9 & 0.694 & \\
Consequences relative & 5 & 0.715 & \\
Control cure of illness & 5 & 0.496 & \\
Control cure by the & 2 & & 0.614 \\
$\quad$ practitioner & & & 0.860 \\
Timeline chronic & 2 & 0.826 \\
Timeline episodic & 2 & & \\
\hline
\end{tabular}

\section{Modified IPQ-SCV subscale correlations}

Table 4 shows the correlations between the modified IPQSCV subscale items. Significant but positive correlations
(0.495, $P<0.001)$ was found between consequences relative and consequences patient and control cure by practitioner and control cure of illness $(0.418, P<0.001)$. The magnitude of the associations between these subscales was moderate. This indicates that LD practitioners have some modest beliefs about the consequences of schizophrenia for relatives being associated with the consequences for the patient. They have similar modest beliefs that the control of schizophrenia exerted by practitioners is associated with the control and cure of the illness generally and by the patient. A significant negative correlation was found between timeline episodic and timeline chronic $(-0.243$, $P<0.001)$. The magnitude of this association was weak indicating that LD practitioners' beliefs that where the presentation of schizophrenia is chronic it is less likely to be episodic with periods of improvement, but that these beliefs are not always held with strong conviction.

\section{Discussion}

The findings from the study have identified the illness perceptions of LD practitioners towards schizophrenia for the first time. Findings related to length of service offer some explanation of potential sources of illness perception. Perceptions regarding the consequences of schizophrenia for people and their relatives and the chronic course of the illness are discussed further as they can influence hope, optimism, recovery and the delivery of family interventions. The discussion can also inform the development of training modules, which can reframe illness perceptions.

\section{Summary of findings}

\section{Length of service and clinical area}

There was variation in the length of service ranging between 1 and 42 years. It is likely many of the staff who have been working in LD services for more than 15 years are staff who have moved from the long-stay hospitals for people with LD. This is further confirmed by the average length of service reported. Illness attitudes formed whilst

Table 3

Descriptive statistics (Mean and Standard Deviation) for Modified IPQ-SCV

\begin{tabular}{|c|c|c|c|c|c|c|}
\hline IPQ subscale & $n$ & Minimum & Maximum & $\begin{array}{l}\text { Possible } \\
\text { maximum }\end{array}$ & Mean & SD \\
\hline Consequences patient & 210 & 7.00 & 22.00 & 45 & 13.136 & 3.051 \\
\hline Consequences relative & 210 & 5.00 & 19.00 & 25 & 11.557 & 3.032 \\
\hline Control: cure by practitioner & 210 & 2.00 & 10.00 & 10 & 7.252 & 1.499 \\
\hline Timeline: chronic & 210 & 1.94 & 10.00 & 10 & 4.042 & 1.510 \\
\hline Timeline: episodic & 210 & 2.00 & 10.00 & 10 & 8.407 & 1.439 \\
\hline
\end{tabular}


Table 4

Pearson's ( $r$ ) correlations for modified IPQ-SCV

\begin{tabular}{|c|c|c|c|c|c|c|}
\hline & $\begin{array}{l}\text { Consequences } \\
\text { patient }\end{array}$ & $\begin{array}{l}\text { Consequences } \\
\text { relative }\end{array}$ & $\begin{array}{l}\text { Control cure } \\
\text { of illness }\end{array}$ & $\begin{array}{l}\text { Control cure by } \\
\text { practitioner }\end{array}$ & $\begin{array}{l}\text { Timeline } \\
\text { chronic }\end{array}$ & $\begin{array}{l}\text { Timeline } \\
\text { episodic }\end{array}$ \\
\hline Consequences patient & - & - & - & - & $->$ & - \\
\hline Consequences relative & $\begin{array}{r}0.495 * * \\
P<0.001\end{array}$ & - & - & - & - & - \\
\hline Control cure of illness & $\begin{array}{c}0.085 \\
P=0.219\end{array}$ & $\begin{array}{l}-0.034 \\
P=0.626\end{array}$ & - & - & - & - \\
\hline Control cure by practitioner & $\begin{array}{c}0.011 \\
P=0.879\end{array}$ & $\begin{array}{l}-0.063 \\
P=0.366\end{array}$ & $\begin{array}{l}0.418^{* *} \\
P<0.001\end{array}$ & & - & - \\
\hline Timeline episodic & $\begin{array}{l}-0.119 \\
P=0.085\end{array}$ & $\begin{array}{l}-0.036 \\
P=0.604\end{array}$ & $\begin{array}{l}0.113 \\
P=0.103\end{array}$ & $\begin{array}{c}0.076 \\
P=0.274\end{array}$ & $\begin{array}{l}-0.243^{* *} \\
P<0.001\end{array}$ & - \\
\hline
\end{tabular}

**Correlation significant at the $P=<0.001$ level $(n=210)$ (two tailed).

working in long-stay hospitals may have perpetuated and be resilient to change.

Other studies have found less positive attitudes in nurses working in hospital settings compared to those working in the community (Linden \& Kavanagh 2012). The study sample included mental health nurses only and drew the conclusion that promotion of community living could explain this difference. Nearly half of the sample in our study still worked in in-patient settings compared to just over a quarter working in the community. This factor could partly explain some of the less positive perceptions reported. There are insufficient data within this study to draw conclusions regarding the enduring nature of illness perceptions and their relationship with moving from inpatient to community work.

\section{Perceptions of recovery}

The mean scores for items on the consequences-patient subscale indicate that LD practitioners in this sample perceive that schizophrenia has a negative effect on adaptation to illness, how others see them, life goals, recovery, career, economic and employability. There is also an overall negative perception of how schizophrenia will impact on achievement and its disabling effects. Our findings indicate that the magnitude of the illness perceptions observed on this subscale may negatively influence LD staff in relation to maintaining therapeutic optimism, which may consequently affect goal setting for recovery. These perceptions lead to low expectations and are a barrier to the recognition of strengths, capacity for achievement and collaboratively planning for employment and other developmental opportunities.

A significant and positive correlation was found between the 'consequences patient' subscale and the 'consequences relative' subscale. The magnitude of this association between these subscales is moderate and is similar to how relatives themselves perceive the consequences for the person with schizophrenia alongside the consequences for themselves (Barrowclough et al. 2001a,b, Lobban et al. 2005). It may be that LD staff attribute some of the negative impact on relatives of those with comorbid LD and schizophrenia to the LD itself. There is evidence that LD does have negative as well as positive implications for families (Reichman et al. 2008). This could explain the limited negative perceptions of consequences for relatives attributed to people with a diagnosis of schizophrenia in this sample.

Recognition of the adverse consequences for relatives may well be a prompt to consider the use of family interventions. Educational family interventions can improve relatives' knowledge about schizophrenia and improve their coping, whilst more intensive family interventions can enhance communication, and problem solving and these can reduce the perceived burden felt by relatives (MacLeod et al. 2011). Family interventions can also facilitate collaborative planning for recovery through involvement of the family in the process (NIHME 2005). One of the other key outcome measures from the use of family interventions has been the reduction of levels of expressed emotion, which is a robust predictor of schizophrenia relapse. A reduction in the level of expressed emotion will reduce the risk of relapse (Pharoah et al. 2010). Relapse may disrupt plans of recovery and optimism in the person with schizophrenia, their relatives and LD staff.

\section{Perceptions of course and chronicity}

Participants in this sample reported that they perceived schizophrenia as a chronic condition and disagreed with the perception that schizophrenia was episodic in nature. The traditional pessimistic view of outcomes for people with schizophrenia has proved to be inaccurate. Longitudinal evidence points to more promising long-term outcomes for people with schizophrenia (Harrow et al. 
2012). The perception by LD staff that schizophrenia is a chronic condition that has limited chance of symptomatic recovery can lead to a pessimistic powerless or 'no hope' view of peoples potential to achieve. Consequently, there may less motivation to implement newer treatments such as psychosocial interventions for the management of schizophrenia symptoms that will also support recovery (Petrie et al. 2008).

A significant negative although weak association was also found between the 'timeline chronic' and 'timeline episodic' subscales. This is important as it suggests that may be some scope within the LD staff perceptions to accommodate an episodic timeline within the strongly perceived chronic timeline of this group. These perceptions could be a target for training programmes that include episodic models of schizophrenia such as the stress vulnerability model (Nuchterlein \& Dawson 1984). Weiner (2010) proposed that causes of failure that are not amenable to change can lead to people becoming hopeless, particularly if that cause of failure is external to the person. If LD practitioners continue to believe that schizophrenia is chronic and not episodic, they are likely to draw conclusions that the person with schizophrenia will not recover and therefore that they are powerless to make any difference to this outcome. It could also increase the possibility that the person with schizophrenia will attribute the failure to recover to schizophrenia being a chronic illness, which is unlikely to improve and indeed may worsen, therefore becoming hopeless.

\section{What the findings adds to scientific evidence}

The current investigation is the first to investigate the illness perceptions specifically of LD practitioners regarding schizophrenia. It has provided some valuable insights into perceptions about consequences for the person and their families and the timeline of the illness. The study findings suggest that reframing an understanding of schizophrenia, its course and the consequences for those with schizophrenia and their relatives would promote a more optimistic attitude and more confidence in people's capacity for recovery (Mason et al. 2009). There is evidence that reframing schizophrenia for staff can instil a strengthsbased recovery-focussed approach where hope is conveyed to the patient and results in greater patient satisfaction, social inclusion and the achievement of life goals (Lester et al. 2003, NIHME 2005). This could potentially allow LD staff to support people with LD to reframe the illness and help people to develop more confidence, an optimistic outlook and personal agency so that they can move on with improved potential for positive outcomes (Andresen et al. 2004).
The findings can be used to support the development of a programme of education to reframe illness perceptions and support a personal recovery approach. Any subsequent improvements in illness perceptions could contribute towards improved outcomes for people with LD and schizophrenia. There may also be benefits for LD staff including reduced stress levels and greater sense of personal achievement (Mills \& Rose 2011).

\section{Limitations of the study}

The current study has a number of limitations. It needs to be acknowledged that the survey methodology prevents any cause and effect conclusions to be drawn.

The study used nonprobability sampling that depended on a specific group of staff agreeing to participate. The findings of the study may not be a true representation of the total population of LD staff as the characteristics of the sample may have influenced the study results. As the sample was limited to one geographical region, generalizing the findings to national and international LD practitioner groups is limited. There is likely to be geographical variations in LD practitioner skills, knowledge and models of service provision. It may be necessary to replicate this study in other geographical regions of the United Kingdom due to the lack of good quality research available in this field at present.

The aim of the strategy to promote the study and to maximize the response rate through the attendance at team meetings may have introduced some bias into the study. Although the investigator left each meeting prior to data collection, attendance at the meeting immediately prior to data collection and by someone known to service staff may have influenced participant responses. It is not possible to gauge the level of influence on participant responses but the potential for bias should be noted.

Further limitations of the study concern the inherent measurement characteristics of the IPQ-SCV itself. To draw reliable insights from the findings, the veracity of the modified IPQ-SCV from a psychometric perspective is important. Two of the six modified IPQ-SCV subscales (timeline chronic and timeline episodic) demonstrated good internal consistency when used with LD practitioners. The values being greater than those found in previous studies of carer and practitioner perceptions of schizophrenia (Lobban et al. 2005, Fleming et al. 2009). Two other subscales (consequences patient and consequences relative) demonstrated acceptable internal consistency similar to those reported by Barrowclough et al. (2001a) and Fleming et al. (2009). The remaining two subscales (control cure of illness and control cure by practitioner) demonstrated poor internal consistency within 
this group of LD practitioners. Similar $\alpha$ values for these subscales have been found in previous studies (Barrowclough et al. 2001a, Fleming et al. 2009) implying a limitation of the tool rather than a participant group characteristic. These subscales may therefore be unreliable for use in this group and more generally.

\section{Implications}

There is limited information from previous studies about the nature of LD practitioners' perceptions of schizophrenia. This study has provided important information about the pessimistic nature of perceptions regarding the consequences, course and chronicity for people with schizophrenia and their carers. Knowing these perceptions and their potential for mediating recovery outcomes can help to inform the development of relevant training and supportive strategies to reframe them.

Monthly training sessions were part of a whole systems approach used by Esan et al. (2012) to introduce recovery-based approaches into an LD service. The findings from our study showed that more than half the participants had not received any additional mental health and/ or recovery training. This finding suggests that recovery training should be made available to LD practitioners and that the training should include modules that cover:

- Bio-psycho-social models of schizophrenia, for example stress vulnerability models emphasize the aetiological role of personal psychological factors such as stress and strongly imply the role of psychosocial interventions in the management of the illness. These models also promote the episodic nature of schizophrenia and consider schizophrenia symptoms within the context of change, the person exerting control and management of symptoms.

- An introduction to the underlying principles of hope and therapeutic optimism. Strategies for embedding these within clinical interventions through wellness recovery action planning, advocacy, strengths-based goal setting, awareness of employment and other developmental opportunities. Case management, clinical supervision and mentorship from recovery champions (Esan et al. 2012) could offer further coaching and guidance on the embedding of the values and principles into clinical practice.

- Family and carer interventions provide families with information about the bio-psycho-social nature of schizophrenia, offer support with communication, managing symptoms and involvement in strengthsbased goal setting (Barrowclough \& Tarrier 1997).

The involvement of people with LD with schizophrenia to contribute to the content and delivery of training is essential. Developing an understanding of the phenomenology of combined LD and schizophrenia and the nature of personal recovery can provide 'real-world' information to inform training modules and clinical practice.

\section{Conclusion}

The study found that across a range of measures of illness perceptions, learning disability practitioners and support workers generally held negative illness perceptions of those with a diagnosis of schizophrenia particularly in relation to the consequences for people with schizophrenia and their relatives, within a learning disability setting. These findings have significant implications in terms of the perceptions of care providers within the context of the compelling evidence base for training in recovery-focused models of care and intervention.

\section{Relevance statement}

Pessimistic illness perceptions within mental health nurses and other health professionals regarding the consequences of schizophrenia on the individual with the diagnosis and their significant others represent important beliefs that are inconsistent with an underlying philosophy of recovery. Awareness of these pessimistic perceptions is important in challenging negative attributions associated with schizophrenia and maximizing recovery by informing relevant training strategies and other clinical interventions.

\section{References}

Amaresha A. \& Venkatsubramanian G. (2012) Expressed emotion in schizophrenia: an overview. Indian Journal of Psychological Medicine 34, 12-20.

Andresen R., Oades L. \& Caputi P. (2004) The experience of recovery from schizophrenia: towards an empirically validated stage model. Australian and New Zealand Journal of Psychiatry 37, 586-594.
Anthony W.A. (1993) Recovery from mental illness: the guiding vision of the mental health service system in the 1990's. Psychosocial Rehabilitation Journal 16, 11-23.

Barrowclough C. \& Hooley J. (2003) Attributions and expressed emotion: a review. Clinical Psychology Review 23, 849-880.

Barrowclough C. \& Tarrier N. (1997) Families of schizophrenic patients. Stanley Thornes, Cheltenham.

Barrowclough C., Lobban F., Hatton C., et al. (2001a) An investigation of models of illness in carers of schizophrenia patients using the illness perception questionnaire. British Journal of Clinical Psychology 40, 371-385.

Barrowclough C., Haddock G., Lowens I., et al. (2001b) Staff expressed emotion and causal attributions for client problems in a low secure unit. Schizophrenia Bulletin 27, 517-526.

Bentall R.P.. (2009) Doctoring the Mind. Why psychiatric treatments fail. Available at: www. penguin.com (accessed Xxx Xxx Xxx).

Bouras N., Martin G., Leese M., et al. (2004) Schizophrenia-spectrum psychoses in people 
with and without intellectual disability. Journal of Intellectual Disability Research 48, 548555.

Campbell M. \& Hogg J. (2008) Impact of training on cognitive representation of challenging behaviour in staff working with adults with intellectual disabilities. Journal of Applied Research in Intellectual Disabilities 21, 561-

574.

Clark L.L. (2007) Learning disabilities within mental health services: are we adequately preparing nurses for the future? Journal of Psychiatric and Mental Health Nursing 14, 433437.

Clark-Carter D. (2010) Quantitative Psychological Research, 3rd edn. Psychology Press, Hove.

Cooper S.A., Smiley E., Finlayson J., et al. (2007) The prevalence, incidence, and factors predictive of mental ill-health in adults with profound intellectual disabilities. Journal of Applied Research in Intellectual disabilities 20, 493-501.

Cronbach L. (1951) Coefficient alpha and the internal structure of tests. Psychometrika 16, 297-334.

Deb S., Thomas M. \& Bright C. (2001) Mental disorder in adults with intellectual disability. 1: prevalence of functional psychiatric illness among a community based population aged between 16 and 64 years. Journal of Intellectual Disability Research 45, 495-505.

DoH (2001) Valuing People: A New Strategy Learning Disability for the 21st Century. Department of Health, London.

DoH (2009) Valuing People Now: A New ThreeYear Strategy for People with Learning Disabilities. Department of Health, London.

Eisinga M., Te Grotenhuis M. \& Pelzer B. (2013) The reliability of a two-item scale: pearson, cronbach, or spearman-brown? International Journal of Public Health 58, 637-642.

Emmerson E., Robertson J. \& Wood J. (2004) Levels of psychological distress experienced by family carers of children and adolescents with intellectual disabilities in an urban conurbation. Journal of Applied Research in Intellectual Disabilities 17, 77-84.

Esan F., Case K., Louis J., et al. (2012) Implementing a patient centred recovery approach in a secure learning disabilities service. Journal of Learning Disabilities and Offending Behaviour 3, 24-34.

Fleming M.P., Martin C.R., Miles J., et al. (2009) The utility of the Illness Perception Questionnaire in the evaluation of mental health practitioners' perspectives on patients with schizophrenia. Journal of Evaluation in Clinical Practice 15, 826-831.

Fortune D., Smith J. \& Garvey K. (2005) Perceptions of psychosis, coping appraisals, and psychological distress in the relatives of patients with schizophrenia: an exploration using selfregulatory theory. British Journal of Clinical Psychology 44, 319-331.

Gliem J. \& Gliem R. (2003) Calculating, Interpreting and Reporting Cronbach's Alpha Reliability Coefficient for Likert-Type Scales. [Online] Available at: https://scholarworks. iupui.edu/bitstream/handle/1805/344/Gliem\% 20\&\%20..?sequence $=1$ (accessed 23 November 2012).

Handley E., Southwell O. \& Steel J. (2012) Recovery and intellectual disabilities: a review. Advances in Mental Health and Intellectual Disabilities 6, 192-198.

Harrow M., Jobe T.H. \& Faull R.N. (2012) Do all schizophrenia patients need antipsychotic treatment continuously throughout their lifetime? A 20-year longitudinal study Psychological Medicine 17, 1-11.

Killaspy H., White S., Lavani N., et al. (2014) The impact of psychosis on social inclusion and associated factors. International Journal of Social Psychiatry 60, 148-154.

Kline P. (2000) Psychometric Primer. Free Association Books, London.

Leamy M., Bird V., Le Boutillier C., et al. (2011) Conceptual framework for personal recovery in mental health: systematic review and narrative synthesis. British Journal of Psychiatry 199, $445-452$.

Lester H., Tritter J. \& England E. (2003) Satisfaction with primary care: the perspectives of people with schizophrenia. Family Practice 20, 508-513.

Levanthal H., Benyami Y., Brownlee S., et al. (1997). Illness representations: Theoretical foundations. In: Perception of Health and Illness: Current Research and Applications (eds Petrie, K.J. \& Weinman, J.A.), pp. 19-45. Harwood Academic Publishers, Amsterdam, Netherlands.

Linden M. \& Kavanagh R. (2012) Attitudes of qualified vs. student mental health nurses towards an individual diagnosed with schizophrenia. Journal of Advanced Nursing 68, 1359-1368.

Lobban F., Barrowclough C. \& Jones S. (2005) Assessing cognitive representations of mental health problems. II. The illness perception Questionnaire for schizophrenia: relatives' version. British Journal of Clinical Psychology 44, 163-179.

MacLeod S.H., Elliott L. \& Brown R. (2011) What support can community mental health nurses deliver to carers of people diagnosed with schizophrenia? Findings from a review of the literature. International Journal of Nursing Studies 48, 100-120.

Martin C.R., Fleming M. \& McCorkindale S. (2016) Measurement properties of the Illness Perception Questionnaire in practitioners working with patients with comorbid schizophrenia and learning disability. European Journal of Person Centred Healthcare 4, 215220.

Mason T., Hall R., Caulfield M., et al. (2009) Forensic nurses perceptions of mental illness and personality disorder: clinical versus management issues. Journal of Psychiatric and Mental Health Nursing 17, 131-140.

Mills S. \& Rose J. (2011) The relationship between challenging behaviour, burnout and cognitive variables in staff working with people who have intellectual disabilities. Journal of Intellectual Disability Research 55, 844-857.

Morgan V.A., Leonard H., Bourke J., et al. (2008) Intellectual disability co-occurring with schizophrenia and other psychiatric illness: population based-study. British Journal of Psychiatry 194, 364-372.

Moss-Morris R., Weinman J., Petrie K., et al. (2002) The Revised Illness Perception Questionnaire (IPQ-R). Psychology \& Health 17, 1-16.

National Institute of Mental Health (2009) A participant's guide to mental health clinical research. What are the risks and benefits of participating in research? [Online] Available at: http://www.nimh.nih.gov/health/publications/aparticipants-guide-to-mental-health-clinical-re search/what-are-the-risks-and-benefits-of-partic ipating-in-research.shtml (accessed 10 October 2012).

NIHME (2005) Guiding Statement on Recovery. National Institute for Mental Health England, London.

Nuchterlein K.H. \& Dawson M.E. (1984) A heuristic vulnerability-stress model of schizophrenia episodes. Schizophrenia Bulletin 10, 300-312.

Petrie K., Broadbent E. \& Kydd R. (2008) Illness perceptions in mental health: issues and potential applications. Journal of Mental Health 17, 559-564.

Pharoah F., Mari J., Rathbone J., et al. (2010) Family interventions for schizophrenia. Cochrane Summaries. [Online] Available at: http://summaries.cochrane.org/CD000088/fam ily-intervention-for-schizophrenia (accessed 17 September 2012).

Reichman N., Corman H. \& Noonan K. (2008) Impact of child disability on the family. Maternal \& Child Health Journal 12, 679-683.

Rose N., Kent S. \& Rose J. (2012) Health professionals' attitudes and emotions towards working with adults with intellectual disability (ID) and mental ill health. Journal of Intellectual Disability Research 56, 854-864.

Scottish Government (2012) Strengthening the Commitment. The Report of the UK Modernising Learning Disability Nursing Review. Scottish Government, Edinburgh.

Scottish Government (2013) Keys to Life. Improving Quality of Life for People with 
Learning Disabilities. Scottish Government, Edinburgh.

Scottish Recovery Network (2010) Evaluation of 10 Essential Shared Capabilities and Realising Recovery training. [Online]. Available at: http://www.scottishrecovery.net/Latest-News/ evaluation-of-10-essential-shared-capabilitiesand-realising-recovery-training.html (accesses 26 July 2010).

Scottish Recovery Network (2012) Recovery. What is recovery? [Online] Available at: http:// www.scottishrecovery.net/What-is-Recovery/ what-is-recovery.html (accessed 29 November 2012).

Sideras S., McKenzie G., Noone J., et al. (2015) Impact of simulation on Nursing students' attitudes towards schizophrenia. Clinical Simulation in Nursing 11, 134-141.

Sivo S., Saunders C., Chang Q., et al. (2006) How low should you go? Low response rates and the validity of inference in IS Questionnaire research. Journal of the Association for Information Systems 7, 351-414.

Slade M., Amering M., Farkas M., et al. (2014) Uses and abuses of recovery: implementing recovery-orientated practices in mental health systems. World Psychiatry 13, 12-20.

Slade M., Bird V., Clarke E., et al. (2015) Supporting recovery in-patients with psychosis through care by community-based adult mental health teams (REFOCUS): a multisite, cluster, randomised, controlled trial. The Lancet 2, 503-514.

Smiley E. (2005) Epidemiology of mental health problems in adults with learning disability: an update. Advances in Psychiatric Treatment 11, 214-222.

Social Exclusion Unit (2004) Mental Health and Social Exclusion. Office of the Deputy Prime Minister/Social Exclusion Unit, London.
SPSS (2009) PASW Statistics. [Online] Available at: http://www.spss.com.hk/statistics/ (accessed 24 October 2012).

Weiner B. (2010) The development of an attribution based theory of motivation: a history of ideas. Educational Psychologist 45, 28-36.

Weinman J. \& Petrie K. (1997) Illness Perceptions: a new paradigm for psychosomatics. Journal of Psychosomatic Research 42, 113 116.

Weinman J., Petrie K., Moss-Morris R., et al. (1996) The illness perception questionnaire: a new method for assessing the cognitive representation of illness. Psychology \& Health 11 431-445.

Welch K.A., Lawrie S.M., Muir W., et al. (2011) Systematic review of the clinical presentation of schizophrenia in intellectual disability. Journal of Psychopathology and Behavioural Assessment 33, 246-253. 


\section{Author Query Form}

Journal: $\quad$ JPM

Article: $\quad 12381$

Dear Author,

During the copy-editing of your paper, the following queries arose. Please respond to these by marking up your proofs with the necessary changes/additions. Please write your answers on the query sheet if there is insufficient space on the page proofs. Please write clearly and follow the conventions shown on the attached corrections sheet. If returning the proof by fax do not write too close to the paper's edge. Please remember that illegible mark-ups may delay publication.

Many thanks for your assistance.

\begin{tabular}{|c|c|c|}
\hline Query reference & Query & Remarks \\
\hline 1 & $\begin{array}{l}\text { AUTHOR: Running title should not exceed a maximum of } 40 \text { characters. } \\
\text { Please check and provide a suitable short title to conform to the journal style. }\end{array}$ & \\
\hline 2 & AUTHOR: Please provide qualifications and job title of all authors. & \\
\hline 3 & $\begin{array}{l}\text { AUTHOR: Please confirm that given names (red) and surnames/family names } \\
\text { (green) have been identified correctly. }\end{array}$ & \\
\hline 4 & AUTHOR: Please check that authors and their affiliations are correct. & \\
\hline 5 & $\begin{array}{l}\text { AUTHOR: Implications has been changed to "Implications for practice". } \\
\text { Please check. }\end{array}$ & \\
\hline 6 & $\begin{array}{l}\text { AUTHOR: Linden \& Kavanagh } 2011 \text { has been changed to Linden and } \\
\text { Kavanagh } 2012 \text { so that this citation matches the Reference List. Please } \\
\text { confirm that this is correct. }\end{array}$ & \\
\hline 7 & $\begin{array}{l}\text { AUTHOR: Leventhal et al. } 1997 \text { has been changed to Levanthal et al. } 1997 \\
\text { so that this citation matches the Reference List. Please confirm that this is } \\
\text { correct. }\end{array}$ & \\
\hline 8 & $\begin{array}{l}\text { AUTHOR: Please check the clarity of the sentence "One-fifth...clos" in } \\
\text { Table } 1 .\end{array}$ & \\
\hline 9 & $\begin{array}{l}\text { AUTHOR: In the sentence "The magnitude...strong conviction", please } \\
\text { suggest whether the phrase "chronic it is less" can be changed to "chronic is } \\
\text { less". }\end{array}$ & \\
\hline 10 & AUTHOR: Please check the placement of the section "Relevance statement". & \\
\hline 11 & $\begin{array}{l}\text { AUTHOR: Please provide Accessed date, month and year for Reference } \\
\text { "Bentall (2009)". }\end{array}$ & \\
\hline 12 & $\begin{array}{l}\text { AUTHOR: Campbell and Hogg (2008) has not been cited in the text. Please } \\
\text { indicate where it should be cited; or delete from the Reference List. }\end{array}$ & \\
\hline 13 & $\begin{array}{l}\text { AUTHOR: Fortune et al. (2005) has not been cited in the text. Please indicate } \\
\text { where it should be cited; or delete from the Reference List. }\end{array}$ & \\
\hline 14 & $\begin{array}{l}\text { AUTHOR: Gliem and Gliem (2003) has not been cited in the text. Please } \\
\text { indicate where it should be cited; or delete from the Reference List. }\end{array}$ & \\
\hline
\end{tabular}




\begin{tabular}{|l|l|l|}
\hline 15 & $\begin{array}{l}\text { AUTHOR: Please check the volume and page range for reference "Harrow } \\
\text { et al. 2012". }\end{array}$ & \\
\hline 16 & $\begin{array}{l}\text { AUTHOR: Levanthal et al. has not been cited in the text. Please indicate } \\
\text { where it should be cited; or delete from the Reference List. }\end{array}$ & \\
\hline 17 & $\begin{array}{l}\text { AUTHOR: Slade et al. (2014) has not been cited in the text. Please indicate } \\
\text { where it should be cited; or delete from the Reference List. }\end{array}$ & \\
\hline 18 & $\begin{array}{l}\text { AUTHOR: Weinman and Petrie (1997) has not been cited in the text. Please } \\
\text { indicate where it should be cited; or delete from the Reference List. }\end{array}$ & \\
\hline 19 & $\begin{array}{l}\text { AUTHOR: Weinman et al. (1996) has not been cited in the text. Please } \\
\text { indicate where it should be cited; or delete from the Reference List. }\end{array}$ & \\
\hline
\end{tabular}

